\title{
Autorización de plantas de revisión técnica e imputación objetiva en delitos culposos del tráfico vehicular
}

\author{
Laura Mayer Lux* \\ Jaime Vera Vega**
}

\begin{abstract}
RESUMEN
El presente trabajo analiza la eventual responsabilidad penal por delitos culposos en virtud de las actuaciones realizadas por las plantas de revisión técnica vehicular. El examen se circunscribe a las reglas técnicas que norman el actuar de dichas plantas revisoras, así como a algunos de los criterios doctrinales de la imputación objetiva, a saber: principio de confianza, riesgo permitido, principio de insignificancia y fin de protección de la norma.
\end{abstract}

Principio de confianza - riesgo permitido - fin de protección de la norma

\section{The licencing of motor vebicle service centers and objective imputation in the act of vebicular traffic negligence}

\begin{abstract}
This paper analyzes the possible criminal liability for the act of negligence by virtue of the actions carried out by motor vehicle service centers. The examination is limited to the technical rules governing the performance of these centers, as well as to some of the doctrinal criteria of objective imputation, namely: trust principle, allowed risk, principle of insignificance and protection purpose of the norm.
\end{abstract}

Trust principle - allowed risk - protection purpose of the norm

* Licenciada en Ciencias Jurídicas y Sociales, Pontificia Universidad Católica de Valparaíso. Doctora en Derecho, Universidad de Bonn, Alemania. Profesora de Derecho Penal, Pontificia Universidad Católica de Valparaíso. Correo electrónico: laura.mayer@pucv.cl.

** Licenciado en Ciencias Jurídicas y Sociales, Pontificia Universidad Católica de Valparaíso. Doctor en Derecho, Pontificia Universidad Católica de Valparaíso. Profesor de Derecho Penal y de Derecho Procesal Penal, Pontificia Universidad Católica de Valparaíso. Correo electrónico: jaime.vera@pucv.cl.

Este trabajo es una versión ampliada de la ponencia, del mismo nombre, presentada en el Seminario Derecho Penal y Tráfico Vehicular, celebrado en la Facultad de Derecho de la Universidad de Chile, los días 24 y 25 de mayo de 2016.

Artículo recibido el 18.1.2017 y aceptado para su publicación en este número el 5.1.2018. 


\section{INTRODUCCIÓN}

C omo es sabido, el tráfico vehicular es una actividad en sí misma riesgosa. En ese sentido, el 2015 fallecieron en Chile 1.646 personas en accidentes de tránsito, mientras que 57.945 sufrieron lesiones en tales circunstancias ${ }^{1}$. Precisamente, los riesgos asociados a la circulación vehicular han hecho necesaria la consagración, tanto a nivel legal como infralegal, de varios instrumentos normativos tendientes a establecer medidas de seguridad estándar, aplicables a quienes intervienen en el tráfico rodado.

Entre dichas medidas podemos distinguir aquellas referidas al comportamiento que deben observar los sujetos que actúan en el tráfico vehicular, así como conductores profesionales, conductores no profesionales y peatones; y aquellas relacionadas con el cumplimiento de medidas técnicas de transporte público, de seguridad de los vehículos y de las vías de circulación. Para los efectos de este trabajo, nos centraremos en el análisis de aquellas normas relativas a las condiciones de seguridad de los vehículos, desperdigadas tanto en el D.F.L. número 1 del 2009, que fija el texto refundido de la Ley de Tránsito, como en el Decreto número 22 del 2006, del Ministerio de Transportes y Telecomunicaciones ${ }^{2}$.

Con el fin de certificar el cumplimiento de dichas exigencias, el artículo 89 de la Ley de Tránsito, ubicado en el Título VII acerca de las revisiones de los vehículos, de sus condiciones de seguridad y de la homologación, consagra un procedimiento de revisión técnica, según lo que determine el Ministerio de Transportes y Telecomunicaciones. Particularmente destacable resulta el inciso segundo del aludido precepto, que fija el ámbito del procedimiento de revisión técnica de los vehículos motorizados, el que debe comprender, en forma especial, los sistemas de dirección, frenos, luces, neumáticos, combustión interna, entre otros aspectos.

Tales revisiones son llevadas a cabo por empresas concesionarias, con fines de lucro, que licitan la prestación de dicho servicio conforme con las condiciones que les fija el Ministerio de Transportes y Telecomunicaciones, a las que conocemos comúnmente como "plantas de revisión técnica" 3 . La normativa a la que estas se ciñen se encuentra prevista en el Decreto número 156 de 1990, emanado del Ministerio de Transportes y Telecomunicaciones, que reglamenta las revisiones técnicas y la autorización y

\footnotetext{
${ }^{1}$ http://www.conaset.cl/programa/observatorio-datos-estadistica/biblioteca-observatorio/estadisticasgenerales/ [visitado el 7/10/2016].

${ }^{2}$ Cuyo título reza: "Dispone requisitos que deben cumplir los sistemas de frenos, luces, señalizadores, aparatos sonoros, vidrios, dispositivos de emergencia y rueda de repuesto con que deberán contar los vehículos motorizados; fija características a casco para ciclista y reglamenta uso de teléfono celular en vehículos motorizados".

${ }^{3}$ Efectivamente, según el artículo $4^{\circ}$ inciso primero de la Ley $\mathrm{N}^{\circ}$ 18.696: "El Ministerio de Transportes y Telecomunicaciones podrá fijar por regiones, provincias o comunas del país establecimientos que practiquen revisiones técnicas a los vehículos que se señale genéricamente y determinará la forma, requisitos, plazo de concesión, causales de caducidad y procedimientos para su asignación y cancelación. Las concesiones respectivas deberán otorgarse mediante licitación pública, al oferente que ofrezca el menor precio por los servicios para la tecnología y calidad técnica especificada en las bases de licitación”.
} 
funcionamiento de las plantas revisoras. Según esta misma normativa, los vehículos motorizados deben someterse a revisiones técnicas con cierta periodicidad, que varía según el tipo de vehículo de que se trate. Este procedimiento de revisión puede tener como resultado una aprobación o un rechazo.

Las plantas de revisión técnica ejercen una función certificadora del cumplimiento de normas legales y reglamentarias que, una vez culminada, da origen a una autorización administrativa. Esta certificación es realizada en virtud de una delegación de facultades administrativas de una entidad pública, como es el Ministerio de Transportes y Telecomunicaciones. Ahora bien, no obstante podría resultar dudoso que estemos ante autorizaciones administrativas en virtud del carácter privado del órgano que las emite, desde el punto de vista de la función que desempeñan las plantas revisoras, de la normativa que las rige y del hecho que el Ministerio de Transportes y Telecomunicaciones pueda encomendarles su cumplimiento ${ }^{4}$, se trata a todas luces de autorizaciones que tienen su fuente última en la intervención de un organismo estatal ${ }^{5}$.

Debido a que, conforme con lo dicho, en el ámbito del tráfico vehicular se contemplan normas acerca de condiciones de seguridad, cuyo cumplimiento debe ser certificado por una planta de revisión técnica, a su respecto surgen distintos problemas relacionados con la imputación objetiva por delitos culposos en el tráfico vial.

En primer lugar, desde la perspectiva de la infracción de las reglas técnicas, deben determinarse los eventuales efectos jurídico-penales que genera la conducción de un vehículo motorizado, habiendo incumplido la obligación de someterse a las inspecciones por parte de una planta de revisión técnica, cuando ello irroga resultados lesivos para la vida o la salud de las personas.

En segundo lugar, está el problema de establecer qué ocurre cuando se realiza una inspección deficitaria de las condiciones de seguridad del vehículo por la planta revisora, y el incumplimiento de dicha condición de seguridad es el factor determinante de la producción de un evento que provoca la muerte o lesiones de otros en el tráfico vial. Desde el punto de vista de la imputación objetiva, el problema consiste en establecer si

${ }^{4}$ Es así como el artículo 90 de la Ley de Tránsito le entrega al Ministerio de Transportes y Telecomunicaciones la facultad de licitar la función que se delega a las plantas de revisión técnica, de lo que podemos desprender que, de no realizarse tal licitación, la función tendría que ser cumplida por organismos públicos. Ello denota que esta actividad se adscribe a una fórmula de gestión de los servicios públicos, propia de un modelo de Estado subsidiario como el chileno.

${ }^{5}$ Esta opinión ha sido defendida en la doctrina administrativa por Rojas, Ch., "Alcance y aplicabilidad de la nulidad administrativa a los actos emanados de particulares en el ejercicio de funciones públicas", en Ferrada, J. C. (coordinador), La nulidad de los actos administrativos en el derecho chileno, Legal Publishing, Santiago, 2013, según quien, las plantas de revisión técnica son personas jurídicas privadas (p. 102), que desarrollan una labor de inspección, enmarcada dentro de la actividad administrativa de policía y que, por lo mismo, implica el ejercicio de autoridad (p. 95). La actividad desplegada por dichas entidades es, además, una función pública en virtud de los bienes jurídicos tutelados que, en opinión de Rojas, corresponderían a la vida e integridad física y psíquica, al derecho a vivir en un medio ambiente libre de contaminación y, más específicamente, a la seguridad vial (p. 101). Finalmente, su labor corresponde a una función acreditativa de contenido declarativo respecto de las condiciones técnicas para la circulación de vehículos, que incluso obliga a la Administración (p. 103). 
es posible que el conductor invoque a su favor el principio de confianza como un criterio que excluya su responsabilidad por los resultados lesivos irrogados.

En tercer lugar, se debe analizar la relación existente entre la autorización concedida por las plantas de revisión técnica y otros criterios que son usualmente abordados por la doctrina respecto de la imputación objetiva de los delitos culposos. Es así como surge la interrogante en orden a si obtener una autorización correctamente otorgada por parte de la planta revisora define, en todo caso, los espacios de riesgo permitido del tráfico vehicular en relación con las condiciones de seguridad que ellas certifican. Luego, se plantea el problema de qué sucede cuando la planta revisora certifica el cumplimiento de las condiciones de seguridad, a pesar de la existencia de defectos menores en los dispositivos inspeccionados, y es posible establecer una conexión causal entre el defecto menor y un resultado lesivo generado por la conducción del vehículo. En esta hipótesis lo que está en juego es la aplicación del principio de insignificancia ${ }^{6}$ como criterio de imputación objetiva. Finalmente, se debe analizar qué ocurre cuando la planta revisora no certifica el cumplimiento de las condiciones de seguridad (sea porque el automóvil no fue sometido a inspección o porque, habiéndolo sido, la certificación fue rechazada) y a pesar de ello el vehículo circula, generándose un resultado lesivo para la vida o la salud de las personas, que no es atribuible al desperfecto del vehículo, sino que proviene de un riesgo diferente. En este caso debe dilucidarse el papel que desempeña el criterio del fin de protección de la norma para efectos de la imputación objetiva.

Con el fin de solucionar los diversos problemas planteados, debemos partir de la base de que la imputación objetiva, en este caso de los delitos culposos, reconoce dos momentos o niveles posteriores al examen de la causalidad: en primer lugar, se debe analizar la imputación objetiva de la conducta, lo que implica establecer si esta creó un riesgo jurídicamente desaprobado para el bien jurídico; en segundo lugar, se debe examinar si el riesgo creado se concretó en el resultado lesivo ${ }^{7}$.

Indudablemente, con este trabajo no se pretende agotar el análisis de todos los problemas que se generan a propósito de la imputación objetiva con motivo de la actuación de las plantas de revisión técnica ${ }^{8}$. Antes bien, lo que se busca es abordar someramente algunas cuestiones que nos han parecido de especial interés para abrir el debate respecto de materias que suponen una reflexión que no puede abarcarse completamente en estas líneas.

Por último, ya que estamos analizando la posible responsabilidad penal por delitos culposos, que en nuestro Derecho solo pueden ser cometidos por personas naturales,

${ }^{6}$ Para el análisis de dicho principio como causal de exclusión de la tipicidad, desde un punto de vista más general, véase Roxin, C., Strafrecht Allgemeiner Teil, Tomo I, 4ª edición, Beck, München, 2006, pp. 298 y s.

${ }^{7}$ Por todos Frisch, W., "Desarrollo, lineamientos y preguntas abiertas sobre la teoría de la imputación objetiva del resultado", trad. de Cecilia Hopp, en Frisch, W., Estudios sobre imputación objetiva, Legal Publishing, Santiago, 2012, p. 31.

${ }^{8}$ Así, por ejemplo, pueden plantearse problemas relativos a otras temáticas de la imputación objetiva, tales como: los poderes superiores e inferiores de los agentes que participan de la revisión; la realización de comportamientos alternativos adecuados a Derecho (v. gr., cuando se logra demostrar que aun habiendo cumplido adecuadamente con la certificación de la condición de seguridad de que se trate, el resultado lesivo se hubiese producido de todas formas); la prohibición de regreso; etcétera. 
cuando hagamos referencia a la actuación de las plantas de revisión técnica, haremos alusión al comportamiento de los sujetos que, directa o indirectamente, participan del proceso de inspección y control de los vehículos.

\section{El CONCEPTO DE REGLA TÉCNICA Y SU VÍNCULO CON LAS AUTORIZACIONES CONCEDIDAS POR PLANTAS DE REVISIÓN VEHICULAR}

\section{Las reglas técnicas en el tráfico vebicular}

En diversos ámbitos de la actividad humana existen normas previstas en leyes, reglamentos o incluso consuetudinariamente, destinadas a establecer medidas de cuidado estandarizadas o "[d]irectrices orientativas" la experiencia general que nos indica cuándo un determinado comportamiento tiene altas probabilidades de generar riesgos para la vida y la salud de las personas ${ }^{10}$. Dichas medidas se denominan, indistintamente, reglas técnicas, reglas generales de cuidado, normas de seguridad o reglas de conducta.

En el contexto del tráfico vehicular abundan esta clase de reglas, previstas tanto en la Ley del Tránsito como en diversas normas infralegales (reglamentos, circulares, instructivos, etc.). En cuanto a las reglas pertinentes a condiciones de seguridad para la circulación vehicular establecidas en la Ley de Tránsito, se deben destacar las contempladas en el Título 5, § 3., denominado: "De las medidas de seguridad". Entre ellas, puede citarse la regla técnica consagrada en el artículo 69, según este: "Los vehículos motorizados deben estar equipados con neumáticos en buen estado (...)”. En relación con las condiciones de seguridad relativas al tráfico vehicular que se hallan establecidas en normas infralegales, puede mencionarse, por ejemplo, la regla técnica del artículo $1^{\circ}$ del Decreto número 22 del 2006, de acuerdo con el cual, los vehículos motorizados deben tener, a lo menos, dos sistemas de frenos de acción independientes uno del otro, y por lo menos uno de estos debe accionar todas las ruedas del vehículo.

La actividad de las plantas de revisión técnica consiste, entre otras materias, en una fiscalización del cumplimiento de ciertas reglas técnicas consagradas en nuestro ordenamiento jurídico, relativas a la circulación vehicular. El problema que puede plantearse respecto de la imputación objetiva de la conducta en los delitos culposos por infracción de las reglas técnicas se refiere a los efectos que genera la concurrencia copulativa de las tres condiciones siguientes: incumplir la obligación de someterse a las inspecciones

\footnotetext{
${ }^{9}$ Freund, G., "Fundamentos de la imprudencia punible. Una contribución desde la regulación alemana", trad. de Jacobo Dopico Gómez-Aller y Laura Pozuelo Pérez, en Donna, E. A. (director), Delitos culposos-II, Rubinzal-Culzoni, Buenos Aires, 2002, p. 94. En un sentido similar Hernández Basualto, H., “Art. 20”, en Couso Salas, J. y Hernández Basualto, H. (directores), Código Penal Comentado, Parte General, Doctrina y Jurisprudencia, Legal Publishing, Santiago, 2011, p. 111.

${ }^{10}$ Véase Corcoy, M., El delito imprudente. Criterios de imputación del resultado, $2^{\mathrm{a}}$ edición, B de $\mathrm{f}$, Montevideo-Buenos Aires, 2005, p. 76.
} 
por parte de una planta de revisión técnica, conducir un vehículo motorizado e irrogar un resultado de muerte o lesiones. En otros términos, un sujeto conduce un vehículo careciendo de una autorización administrativa que avale el cumplimiento de las condiciones de seguridad estándar para la circulación vehicular, y provoca con su circulación la muerte o lesiones de otro(s). La duda que surge es si basta con la verificación de las condiciones indicadas para que se dé el presupuesto de imputación objetiva del delito culposo o si, en cambio, deben concurrir exigencias adicionales. La respuesta a esta interrogante requiere de un examen previo respecto del papel que cumple la infracción de las reglas técnicas en la imputación objetiva de la conducta en los delitos culposos.

De acuerdo con la doctrina dominante, el presupuesto de imputación objetiva en los delitos culposos es la infracción del deber de cuidado ${ }^{11}$ a partir del que se crea un riesgo jurídicamente desaprobado. Ahora bien, la infracción del deber de cuidado no debe confundirse con la vulneración de la regla técnica. En ese sentido, es posible que se infrinjan reglas técnicas y que no exista una vulneración del deber de cuidado, así como que exista una infracción del deber de cuidado sin que ello suponga una vulneración de alguna regla técnica. En esa línea, la doctrina plantea que la infracción de las reglas técnicas solo puede constituir un indicio de la vulneración del deber de cuidado, no así un elemento determinante para que concurra dicha infracción ${ }^{12}$.

En nuestra opinión, el carácter indiciario de la vulneración del deber de cuidado que supone la infracción de las reglas técnicas encuentra un sustento en el Derecho positivo penal chileno. En ese orden de ideas, el artículo 492 del Código penal, en su inciso primero, dispone que " $[1]$ as penas del artículo 490 se impondrán también respectivamente al que, con infracción de los reglamentos y por mera imprudencia o negligencia, ejecutare un hecho o incurriere en una omisión que, a mediar malicia, constituiría un crimen o un simple delito contra las personas" (cursivas agregadas). Consiguientemente, dicho precepto reconoce que la falta de diligencia (esto es, la infracción del deber de cuidado) y la vulneración del reglamento (regla técnica) constituyen requisitos autónomos e independientes para la tipicidad del comportamiento culposo ${ }^{13}$.

Con todo, la infracción del deber de cuidado y la infracción de la regla técnica no pueden entenderse como dos exigencias del todo desligadas. En cambio, la infracción del reglamento debe estar vinculada con el cuidado que la persona debe aplicar en el ámbito

${ }^{11}$ Así, por ejemplo, Hirsch, H. J., "Sobre lo injusto del delito imprudente", trad. de Eduardo Demetrio Crespo, en Revista de Derecho Penal y Criminología, 2a época, núm. 16, 2005, p. 210; Mañalich, J. P., "La imprudencia como estructura de imputación”, en Revista de Ciencias Penales, 6a época, vol. XLII, núm. 3 , 2015, p. 21; Zugaldía Espinar, J. M., "La infracción del deber individual de cuidado en el sistema del delito culposo", en Anuario de Derecho Penal y Ciencias Penales, 1984, p. 327.

12 Véase Schünemann, B., "Las reglas de la técnica en Derecho penal”, trad. de Manuel Cancio y Mercedes Pérez, en Schünemann, B., Obras, Tomo II, Rubinzal-Culzoni, Buenos Aires, 2009, p. 271. En la doctrina nacional, véase asimismo Reyes, I., "Una aproximación a la imputación a título de imprudencia en el Código penal chileno", en Revista de Derecho de la Pontificia Universidad Católica de Valparaíso, vol. XLVII, 2016, p. 254.

${ }^{13}$ En el mismo sentido Cury, E., Derecho penal, Parte general, $10^{\text {a }}$ edición, Ediciones Universidad Católica de Chile, Santiago, 2011, p. 342. 
de relación en que se sitúa ${ }^{14}$. O sea, la regla técnica debe vincularse con el ámbito de riesgo en el que interviene el sujeto, en cuyo contexto se verifica la infracción del deber de cuidado. En suma, en ámbitos de actividad normados por reglas técnicas, el presupuesto de imputación objetiva de los delitos culposos comprende dos niveles, autónomos pero relacionados: la infracción de la regla técnica y la infracción del deber de cuidado.

Si llevamos esta idea al tema que nos ocupa, podemos concluir que quien conduce un vehículo motorizado, habiendo incumplido la obligación de someterse a las inspecciones por parte de una planta de revisión técnica, e irroga un resultado lesivo para la vida o salud de otros intervinientes en el tráfico vehicular, puede o no responder por un delito culposo. Esto dependerá de si el conductor, además de infringir su deber de contar con una autorización administrativa para circular, emanada de una planta de revisión técnica, vulnera el deber de cuidado exigible para el ámbito de relación de que se trate. Desde luego, dejamos fuera de la imputación objetiva por delito culposo el mero incumplimiento del deber de someterse a las inspecciones aludidas, que solo puede dar lugar a responsabilidad administrativa ${ }^{15}$. Por el contrario, con el fin de no transformar estos delitos en infracciones de mera desobediencia, quien incumple la obligación de someterse a las inspecciones por parte de una planta de revisión técnica debe, al mismo tiempo, vulnerar su obligación de conducir según las condiciones de seguridad establecidas en la normativa vigente y las medidas de cuidado que le son exigibles en el caso concreto. Asimismo, el solo cumplimiento del deber de someterse a las inspecciones no excluye la imputación objetiva por delito culposo si es que se vulnera la obligación de manejar un vehículo de acuerdo con las condiciones de seguridad establecidas y las medidas de seguridad exigibles. Para explicar lo señalado, considérense las siguientes situaciones hipotéticas:

Primera situación: A conduce su vehículo un día soleado y despejado a una velocidad razonable y prudente. El conductor ha incumplido su obligación de someter el vehículo a la revisión periódica por parte de una planta revisora y el limpiaparabrisas no funciona. A colisiona a otro vehículo, que no pudo frenar a tiempo y cruzó el eje central de la calzada, colisión a raíz de la cual el conductor del segundo vehículo muere. En un caso como el indicado hay infracción de la regla técnica consistente en someterse a la revisión periódica del vehículo. Además, A infringe una condición de seguridad del vehículo, cuyo cumplimiento es certificado por las plantas revisoras, pues el limpiaparabrisas no funciona. Finalmente, existe un resultado lesivo para la vida de otra persona. Sin embargo, este no es imputable objetivamente a la infracción de la regla técnica cometida por A, quien observó el cuidado que le era exigible en el caso concreto. En otras palabras, su actuar no es

${ }^{14}$ En esa línea Bustos, J., El delito culposo, Editorial Jurídica de Chile, Santiago, 1995, p. 54.

${ }^{15}$ En este caso, dicha responsabilidad proviene de una infracción grave, establecida en el artículo 200 número 18 de la Ley de Tránsito, y acarrea las sanciones establecidas en el artículo 204 de la referida Ley, que son impuestas por el Juez de Policía Local competente. 
creador de un riesgo jurídicamente desaprobado por el Derecho, con lo que no se cumple el primer nivel de imputación objetiva en los delitos culposos ${ }^{16}$.

Segunda situación: A conduce un vehículo un día de intensas lluvias, que dificultan la visibilidad en el tráfico rodado. El conductor ha cumplido su obligación de someter el vehículo a la revisión periódica por parte de una planta revisora, pero, con posterioridad a dicha revisión, el limpiaparabrisas sufre un desperfecto que impide su funcionamiento. Producto de las intensas lluvias, A carece de la visibilidad necesaria para conducir, como consecuencia de ello colisiona a otro vehículo, cuyo conductor muere. En un supuesto como el indicado no hay infracción de la regla técnica consistente en someterse a la revisión periódica del vehículo. Sin embargo, existe un resultado lesivo para la vida de otra persona, que le es imputable objetivamente a $A$, pues al circular con el limpiaparabrisas en mal estado de funcionamiento un día de intensas lluvias, no observó el cuidado que le era exigible en el caso concreto. En otros términos, su actuar es creador de un riesgo jurídicamente desaprobado por el Derecho, con lo que se cumple el primer nivel de imputación objetiva en los delitos culposos.

\section{EL PRINCIPIO DE CONFIANZA EN EL MARCO DE LA ACTIVIDAD DESARROLLADA POR LAS PLANTAS DE REVISIÓN VEHICULAR}

De acuerdo con la fórmula tradicional del principio de confianza en materia penal, una relación está regida por este "cuando el que obra de modo conforme a Derecho en su ámbito de organización puede partir de que los demás también lo harán en el suyo, salvo que se haga evidente lo contrario" ${ }^{17}$. El principio de confianza encuentra límites en el denominado principio de defensa, en virtud de esto, "el interviniente en el tráfico queda obligado a prevenir el defectuoso comportamiento de los demás, sobre todo en el caso de niños, ancianos y minusválidos" ${ }^{18}$.

El principio de confianza ha tenido una de sus más importantes aplicaciones en el contexto del tráfico viario, si bien hoy se le invoca en términos mucho más amplios ${ }^{19}$,

${ }^{16}$ Sin perjuicio de que en un caso como el indicado podría estimarse que no existe injusto culposo porque el riesgo creado no se realiza en el resultado típico, estimamos que otra forma de interpretar esta cuestión pasa por considerar que aquí solo hay una infracción de la regla técnica y no una vulneración del deber de cuidado. En este contexto, la ausencia del injusto culposo se produce por la falta del primer nivel de imputación objetiva, esto es, la infracción de un deber de cuidado que cree un riesgo jurídicamente desaprobado para el bien jurídico.

${ }^{17}$ Silva Sánchez, J., "Deberes de los miembros de un Consejo de Administración [a propósito de la STS núm. 234/2010 (Sala de lo Penal), de 11 de marzo]", en InDret, 2011, p. 1, quien, sin embargo, defiende una formulación diversa de dicho principio.

${ }^{18}$ Corcoy, M., El delito imprudente. Criterios de imputación del resultado, $2^{\mathrm{a}}$ edición, B de f, MontevideoBuenos Aires, 2005, p. 319.

${ }^{19}$ Así Welzel, H., Derecho penal alemán, trad. de Juan Bustos y Sergio Yáñez, $4^{a}$ edición, Editorial Jurídica de Chile, Santiago, 1997, p. 159. 
respecto de todas aquellas actividades sociales en las que participa una pluralidad de sujetos, sobre todo cuando se trata de actuaciones en equipo con división del trabajo ${ }^{20}$. Ahora bien, la aplicación que se ha efectuado de dicho principio en el ámbito del tráfico vehicular se ha circunscrito especialmente a la relación que se verifica entre los distintos interactuantes en dicho tráfico, en el sentido de que sería posible confiar en la actuación conforme a Derecho de parte de los mismos ${ }^{21}$.

Según lo indicado supra, las plantas de revisión técnica otorgan una autorización administrativa, que certifica el cumplimiento de ciertas condiciones de seguridad para la circulación vehicular. En este contexto, surge el problema de establecer qué ocurre si se efectúa una inspección deficitaria de las condiciones de seguridad del vehículo de parte de la planta revisora, y el incumplimiento de esa condición de seguridad es el factor determinante de la generación de un evento que causa la muerte o lesiones de otros en el tráfico vial. Por su parte, en términos de la imputación objetiva surge la siguiente interrogante: ¿Puede el particular invocar el principio de confianza para quedar liberado de responsabilidad por delito culposo? Si la respuesta a esta pregunta es afirmativa, nos encontraríamos ante una aplicación del principio de confianza en el marco del tráfico viario, pero en una relación que es diferente de la que paradigmáticamente ha reconocido la doctrina como ámbito en el que puede invocarse este principio para excluir la imputación objetiva.

En efecto, no se trata en este caso de una aplicación del principio de confianza entre interactuantes del tráfico vial, como conductores o peatones. Antes bien, nos hallamos frente a un supuesto en que un particular invoca esta causal de exclusión de la imputación objetiva por delito culposo, respecto de la intervención de un organismo que actúa en el ejercicio de una función pública, certificando el cumplimiento de las condiciones técnicas de seguridad de un vehículo, previstas en la normativa legal y reglamentaria.

En la aplicación del principio de confianza en supuestos distintos del tráfico vehicular, en los que existen actuaciones en equipo con división del trabajo, suele distinguirse entre relaciones horizontales y verticales ${ }^{22}$. Las relaciones horizontales se caracterizan porque todos los interactuantes en un determinado contexto se encuentran en un mismo nivel, o bien, en niveles equivalentes; mientras que las relaciones verticales implican la existencia de distintos niveles o de un vínculo jerárquico entre quienes interactúan. En otras palabras, las relaciones horizontales se dan en un plano de igualdad jerárquica y

${ }^{20}$ Véase Anarte, E., Causalidad e imputación objetiva en derecho penal: estructura, relaciones y perspectivas, Universidad de Huelva, Huelva, 2002, pp. 299 y s. En la doctrina nacional, véase asimismo Fernández, J. A., "El delito imprudente: la determinación de la diligencia debida en el seno de las organizaciones", en Revista de Derecho, Universidad Austral de Chile, vol. XIII, 2002, pp. 115 y ss.

${ }^{21}$ En ese sentido Etcheberry, A., Derecho Penal, Parte General, Tomo I, reimpresión de la $3^{\text {a }}$ edición, Editorial Jurídica de Chile, Santiago, 2010, pp. 316 y s.

${ }^{22}$ Con referencia al ámbito de la responsabilidad penal por imprudencia médica, véase Rosas, J. I., "La delimitación del deber de cuidado en la imputación de responsabilidad penal por imprudencia médica", en Doctrina y jurisprudencia penal, n 5. Imprudencia penal médica, 2011, p. 22. 
las relaciones verticales se dan un plano de subordinación jerárquica ${ }^{23}$. Ejemplo de las primeras es el vínculo que se presenta entre el cirujano y el anestesista; supuesto de las segundas es el que se verifica entre el jefe de planta y sus empleados ${ }^{24}$.

Sin embargo, tratándose de la relación que se da entre los agentes de la planta de revisión técnica y la persona que somete su vehículo al control e inspección de dicha planta, no puede sostenerse la existencia de un vínculo horizontal ni vertical. En efecto, no es posible afirmar que se presente una división del trabajo entre la planta revisora y quien somete su vehículo a control e inspección, lo que impide la existencia de relaciones de igualdad o subordinación jerárquica. En nuestra opinión, esto no impide apreciar la existencia de un vínculo de naturaleza diversa, en el que de todos modos resulte aplicable el principio de confianza.

La relación entre la planta de revisión técnica y la persona que somete su vehículo a control e inspección se caracteriza porque este último contrata un servicio de la primera. Aunque exista un contrato, no puede hablarse de horizontalidad, pues la ley obliga al responsable del vehículo a contratar, de suerte que si no lo hace, incurrirá en responsabilidad administrativa. Además, la planta actúa como una entidad experta en la supervisión de las condiciones técnicas de seguridad del vehículo y puede aprobar o rechazar la inspección efectuada. Por otra parte, tampoco se trata de un vínculo de subordinación, ya que a las plantas de revisión técnica se les encomienda el desarrollo de una función pública, para cuyos efectos actúan por delegación del Ministerio de Transportes y Telecomunicaciones. En ese sentido, no corresponde afirmar una relación de subordinación del ciudadano respecto de un ente particular al que se le ha encomendado una función pública, ya que el Estado, por mandato constitucional, debe actuar siempre en servicio de la persona.

No obstante, el principio de confianza puede tener aplicación respecto de las actuaciones de las plantas de revisión técnica, en el siguiente sentido: según lo indicado supra, dichas plantas revisoras son entidades expertas en el control e inspección de las condiciones técnicas de seguridad de un vehículo, que actúan por delegación de una autoridad administrativa y están bajo su control. En esas circunstancias, quien somete su vehículo a la supervisión de una de estas plantas -que son por lo demás las únicas facultadas para realizarla- puede estimar razonablemente que la planta revisora actuará conforme con la normativa legal, reglamentaria y técnica que la rige. Así, por ejemplo, quien presenta su vehículo a la supervisión de la planta revisora, que aprueba el control y la inspección, indicando que solo existe un defecto menor en las luces del vehículo, puede confiar en que dicho defecto realmente es menor, y que además no existen otros defectos para la seguridad vehicular. De forma que si se genera un resultado lesivo para la vida o salud de otros, en que la creación del riesgo proviene de una revisión deficitaria

${ }^{23}$ Véase Fernández, J. A., "El delito imprudente: la determinación de la diligencia debida en el seno de las organizaciones”, en Revista de Derecho, Universidad Austral de Chile, vol. XIII, 2002, p. 116.

${ }^{24}$ Así Feijóo, B., "El principio de confianza como criterio normativo de imputación en el derecho penal: Fundamento y consecuencias dogmáticas”, en Derecho penal y criminología, vol. 21, núm. 69, 2000, p. 54. 
de la planta, dicho resultado no podrá ser imputado objetivamente al comportamiento del conductor del vehículo ${ }^{25-26}$.

Cuando se dan las condiciones para que el conductor invoque el principio de confianza, corresponde determinar el efecto que ello produce desde el punto de vista de la imputación objetiva. A nuestro juicio, y de acuerdo con lo planteado por Corcoy, el principio de confianza permite excluir la imputación objetiva de la conducta, ya que opera como criterio de selección de los comportamientos peligrosos de terceros que deben ser abarcados por el deber objetivo de cuidado ${ }^{27}$. En consecuencia, no integra el deber de cuidado del conductor del vehículo el hecho que la planta haya realizado una inspección correcta del mismo. En otras palabras, como no es razonablemente esperable el comportamiento defectuoso de la planta revisora, el conductor puede partir de la base de que la revisión está en orden y que, en consecuencia, su vehículo está en condiciones adecuadas para la circulación.

Ahora bien, el principio de confianza solo puede operar para excluir la imputación objetiva de la conducta en los términos señalados, cuando no existan evidencias concretas del comportamiento incorrecto de aquel en quien se confía ${ }^{28}$. Si aplicamos esto a la relación entre el conductor del vehículo inspeccionado y la planta de revisión técnica, es posible afirmar que el primero puede confiar en la conducta de la segunda, en la medida

25 En un caso como este podría afirmarse que el técnico de la planta debe responder como autor mediato del delito culposo (así del Castillo, E., La imprudencia: autoría y participación, Dykinson, Madrid, 2007, pp. 175 y ss.), mientras que el conductor del vehículo se encontraría en una hipótesis de error de tipo respecto de la conducta infractora del deber de cuidado. Lo anterior se sustenta en que la obtención de la autorización administrativa produce en el conductor una representación equivocada acerca de los riesgos que puede controlar en la conducción vehicular.

${ }^{26}$ A la inversa, en nuestra opinión, las plantas de revisión técnica no podrían invocar la aplicación del principio de confianza respecto del comportamiento de quienes someten sus vehículos a la inspección y control de las mismas. Ello se debe a que nos encontramos ante un supuesto en que la planta revisora actúa en el ejercicio de una función de vigilancia y control de la actuación de un tercero (en términos análogos, desde una perspectiva más general, Duttge, G., Zur Bestimmtheit des Handlungsunwerts von Fabrlässigkeitsdelikten, Mohr Siebeck, Tübingen, 2001, p. 469). Precisamente, en estos casos, se afirma que quien tiene la función de supervigilancia no puede invocar en su beneficio el principio de confianza, ya que es su actividad la que garantiza la existencia de ciertas condiciones para el disfrute de los bienes jurídicos, condiciones que en esta hipótesis apuntan a la seguridad en el tráfico vehicular. Esta calidad de garante es la que justifica la confianza que otros depositan en su conducta (en un sentido similar Abraldes, S., Delito imprudente y principio de confianza, Rubinzal-Culzoni, Buenos Aires, 2010, pp. 361 y ss.). Así, por ejemplo, estimamos que si el particular intenta engañar a la planta de revisión técnica, acudiendo a esta en un vehículo con neumáticos recauchados o redibujados, de una manera que hace casi imperceptible la existencia del defecto, la planta revisora no podría invocar el principio de confianza respecto de la conducta del particular. Eso no significa necesariamente que el agente de la planta deba responder por el defecto no advertido en el neumático: su responsabilidad dependerá de si en la inspección cumplió con todas las medidas necesarias para advertir la existencia del defecto. En caso de no advertirlo habiendo incumplido su deber de cuidado, responderá como autor por la infracción de dicho deber.

${ }^{27}$ Véase Corcoy, M., El delito imprudente. Criterios de imputación del resultado, $2^{a}$ edición, B de f, Montevideo-Buenos Aires, 2005, p. 321.

${ }^{28}$ Véase Abraldes, S., Delito imprudente y principio de confianza, Rubinzal-Culzoni, Buenos Aires, 2010, p. 337 . 
en que no existan evidencias concretas de una inspección deficiente de los mecánicos de la planta revisora. Por otra parte, si el conductor, tras la revisión de su vehículo, percibe la presencia de un defecto en este ${ }^{29}$, retoma el control del riesgo y el peligro respectivo pasa a integrar su deber de cuidado. Consiguientemente, de producirse un resultado lesivo para terceros, no podría invocar el principio de confianza y la creación de dicho riesgo le sería imputable objetivamente.

\section{RIESGO PERMITIDO, PRINCIPIO DE INSIGNIFICANCIA, FIN DE PROTECCIÓN DE LA NORMA Y CONTROL REALIZADO POR LAS PLANTAS DE REVISIÓN VEHICULAR}

Tradicionalmente, uno de los criterios que se ha utilizado para delimitar la imputación objetiva de la conducta es el del denominado "riesgo permitido". En virtud del mismo, se acepta "que en el marco de la realización de actividades arriesgadas existen determinados espacios que ya desde un principio no se hallan abarcados por las normas penales de comportamiento por responder a una configuración vital que es tolerada de modo general" 30 . También es común que se atribuya a dicho criterio el efecto de excluir la imputación objetiva de la conducta ${ }^{31}$, por estimarse que uno de los presupuestos de tal imputación es la creación de un riesgo jurídicamente desaprobado para el bien jurídico.

Uno de los ámbitos en los que se ha planteado la aplicación del criterio del riesgo permitido es el de actividades que son generadoras de riesgos, pero que se permiten en determinadas circunstancias, por ser de prevalente utilidad social ${ }^{32}$. En algunos casos dichas actividades se encuentran reglamentadas, como ocurre con el funcionamiento de industrias, la realización de competiciones deportivas y, en lo que aquí interesa, el tráfico rodado ${ }^{33}$.

Para desarrollarse dentro de márgenes tolerables, el tráfico vehicular-que es una actividad per se riesgosa- requiere la verificación de un cúmulo de condiciones, entre las que se cuenta la existencia de normas que fijan parámetros abstractos de cuidado a

${ }^{29}$ En estas circunstancias podría generarse responsabilidad para el conductor en dos hipótesis: si se trata de defectos perceptibles por un hombre medio; o bien, si se trata de defectos que el conductor pudo percibir de acuerdo con sus conocimientos especiales.

${ }^{30}$ Cancio, M., “Aproximación a la teoría de la imputación objetiva”, en Bolaños, M. (compiladora), Imputación Objetiva y Dogmática Penal, Universidad de Los Andes, Mérida, 2005, p. 96.

${ }^{31}$ Véase Roxin, C., Strafrecht Allgemeiner Teil, Tomo I, 4a edición, Beck, München, 2006, p. 382. A partir de ello es que nuestra doctrina considera que el riesgo permitido constituye una causal de atipicidad. Véase Garrido, M., Derecho Penal, Parte General, Tomo II, reimpresión de la $4^{\text {a }}$ edición, Editorial Jurídica de Chile, Santiago, 2007, p. 218.

${ }^{32}$ En un sentido análogo Gössel, K. H., "Viejos y nuevos caminos de la teoría de la imprudencia (Fabrlässigkeitslehre)", en Donna, E. A. (director), Delitos culposos-I, Rubinzal-Culzoni, Buenos Aires, 2002, p. 26. Véase también, en la doctrina nacional, Reyes, I., "Un concepto de riesgo permitido alejado de la imputación objetiva”, en Revista Ius et Praxis, núm. 1, 2015, pp. 141 y s.

${ }^{33}$ Véase Cancio, M., “Aproximación a la teoría de la imputación objetiva”, en Bolaños, M. (compiladora), Imputación Objetiva y Dogmática Penal, Universidad de Los Andes, Mérida, 2005, p. 97. 
nivel legal o infralegal ${ }^{34}$. En este contexto, la certificación que efectúan las plantas de revisión técnica es manifestación de esa normativa que determina estándares de cuidado. En otras palabras, el deber -impuesto normativamente- de someter un vehículo a revisiones periódicas para supervisar el cumplimiento de ciertas condiciones de seguridad, tiene por finalidad disminuir los peligros que están asociados al tráfico vial.

Frente a lo expresado, surge la interrogante de si siempre que el vehículo haya sido sometido a un control por parte de una planta de revisión técnica y este se haya realizado cumpliendo cabalmente la normativa que lo rige, nos hallaremos dentro del ámbito del riesgo permitido ${ }^{35}$, que excluye la imputación objetiva de la conducta. Como podrá advertirse, el supuesto de hecho que planteamos es el inverso al que se analizó a propósito del principio de confianza, pues mientras en este último caso partíamos de la realización de un control defectuoso de la planta revisora, en el ámbito del riesgo permitido se trata de la ejecución de un control ajustado a la normativa. Sin embargo, al igual como sostuvimos en relación con el principio de confianza, no es posible afirmar una exclusión absoluta de la imputación objetiva cuando opera el riesgo permitido en este contexto.

A nuestro juicio, la circunstancia de haber sorteado exitosamente el control jurídicamente correcto de la planta revisora transforma, a priori, al tráfico vehicular en una actividad que se enmarca dentro del riesgo permitido. Ello obedece a que la conducción vehicular es una práctica de utilidad social, respecto de la cual quien la ejecuta, además, se ha sometido a la normativa que la rige. Esta conclusión debe ser matizada cuando el conductor, no obstante haber superado satisfactoriamente el control de la planta revisora, advierte la existencia de una circunstancia que podría generar un riesgo para la circulación, relativa a aquellos dispositivos que fueron supervisados. Así, por ejemplo, quien habiendo sorteado la revisión técnica, circula camino abajo por una pendiente, cumpliendo con todas las restantes medidas de cuidado que exige el tráfico imperante, sufre un desperfecto imprevisto en sus frenos y atropella a unos peatones, podría invocar el riesgo permitido para ver excluida su responsabilidad penal. En cambio, si en esa misma hipótesis el conductor había advertido un funcionamiento inadecuado de sus frenos, no puede invocar dicho criterio, pues la circunstancia percibida altera las condiciones de previsibilidad (ex ante) del peligro ${ }^{36}$.

En efecto, el hecho que el conductor supere el control de la planta revisora tiene incidencia en la previsibilidad (ex ante) de los riesgos que podrían crearse con motivo de aquellas condiciones de seguridad, cuyo cumplimiento es certificado. En ese sentido,

${ }^{34}$ Mayer Lux, L. y Vera Vega, J., "Relevancia jurídico-penal de la conducción vehicular sin la correspondiente licencia”, en Doctrina y Jurisprudencia Penal, Edición Especial, 2014, pp. 121 y s.

${ }^{35}$ En el sentido de que, en general, el cumplimiento de reglas técnicas permite que nos encontremos dentro del ámbito del riesgo permitido, Jakobs, G., "La imputación objetiva, especialmente en el ámbito de las instituciones jurídico-penales del 'riesgo permitido', la 'prohibición de regreso' y el 'principio de confianza'”, trad. de Enrique Peñaranda, en Jakobs, G., Estudios de Derecho Penal, Civitas, Madrid, 1997, p. 213. Desde un punto de vista más general Kindhäuser, U., “Acerca de la delimitación entre dolo e imprudencia”, trad. de Orlando Humberto De La Vega, en Revista Jurídica - Mario Alario D’Filippo, vol. 4, núm. 1, 2012, p. 18.

${ }^{36}$ En un sentido similar, pero desde una perspectiva general, Ovalle, G., "Imprudencia y cognición", en Doctrina y jurisprudencia penal, $n^{\circ} 4$. Imprudencia penal. Cuestiones generales, 2011, p. 42. 
el control realizado por la planta de revisión técnica disminuye, para el conductor, la previsibilidad (ex ante) de que pueda ocurrir un evento lesivo para la vida o salud de terceros, que tenga su origen en un desperfecto del vehículo relacionado con el funcionamiento de su sistema de dirección, frenos, luces, neumáticos, combustión interna, entre otros. Sin embargo, cuando interfieren elementos distintos de la certificación de la planta revisora, así como la existencia de conocimientos ${ }^{37}$ o capacidades ${ }^{38}$ especiales $^{39}$, o el hecho de haber advertido o haber debido advertir la presencia de algún desperfecto vinculado con los dispositivos controlados, resurge la previsibilidad objetiva del peligro y el conductor debe responder.

En otro orden de cosas, a propósito de la imputación objetiva es posible establecer un vínculo entre el control al que es sometido un vehículo en una planta de revisión técnica y el principio de insignificancia. Así, de lo que se trata es de determinar si se puede imputar objetivamente aquel resultado que se origina, en alguna medida, en aquellos defectos que por su menor entidad no obstan al otorgamiento de un certificado de revisión técnica. Es posible hacer presente que entre la normativa del Ministerio de Transportes y Telecomunicaciones respecto de la actividad de las plantas revisoras se contemplan manuales de procedimientos e interpretación de resultados aplicables a las tres clases de revisión técnica que se prevén en nuestro país (A1, A2 y B). En ellos se distinguen dos clases de defectos que se pueden presentar en los vehículos. Por una parte, están los defectos menores, que corresponden a aquellos de carácter incipiente, que no revisten un peligro claro para la circulación ${ }^{40}$, a pesar de ello pueden acarrear una sanción en caso de ser detectados en la vía pública ${ }^{41}$. Por otra parte, están los defectos graves, que corresponden a aquellos que revisten un peligro para la circulación ${ }^{42}$, cuya existencia demanda una nueva inspección -en la que solo se verifica el aspecto defectuoso- y provoca que el vehículo no sea apto para circular.

${ }^{37}$ V. gr., el conductor de un vehículo sabe que cierta partida de neumáticos de una fábrica presenta defectos muy difíciles de advertir y que en caso de falla pueden provocar el desprendimiento de la banda de rodadura de los mismos. No obstante ese conocimiento, instala los neumáticos por su menor precio, el vehículo supera el control de la planta revisora, la banda de uno de los neumáticos del vehículo se desprende y colisiona a otro conductor, que muere.

38 Por ejemplo, el conductor es un mecánico profesional y, en virtud de sus capacidades especiales, percibe en su vehículo un sonido que constituye un signo inequívoco de un mal funcionamiento del sistema de frenos. Sin embargo, decide proseguir la conducción, se cortan sus frenos y atropella a un peatón, lesionándolo.

${ }^{39}$ Destaca la importancia de estos conocimientos y capacidades para determinar el contenido ilícito de un delito culposo van Weezel, A., "Parámetros para el enjuiciamiento de la infracción al deber de cuidado en los delitos imprudentes", en Revista Chilena de Derecho, vol. 26, núm. 2, 1999, p. 324. En un sentido similar Kindhäuser, U., “QQué es la imprudencia?”, trad. de Juan Pablo Mañalich, en La Ciencia Penal en la Universidad de Chile, Libro Homenaje a los Profesores del Departamento de Ciencias Penales de la Facultad de Derecho de la Universidad de Chile, LOM, Santiago, 2013, p. 224.

${ }^{40} \mathrm{O}$ para los pasajeros, tratándose de las revisiones técnicas tipo A1 (buses).

${ }^{41}$ Los documentos relativos a diversas hipótesis de defectos pueden revisarse en el siguiente sitio web: http://www.prt.cl/Paginas/Documentos.aspx [visitado el 7/10/2016].

${ }^{42} \mathrm{O}$ para los pasajeros, tratándose de las revisiones técnicas tipo A1 (buses). 
Tomemos en cuenta el siguiente supuesto: un vehículo es sometido al control de la planta revisora, obtiene la certificación, en la que sin embargo se señala que existe una diferencia en el frenado de las ruedas de un mismo eje, el que es calificado como "defecto menor". Luego, el conductor, habiendo cumplido con toda la normativa que rige el tráfico vehicular, atropella a un peatón, lesionándolo. Mediante prueba pericial se logra acreditar que, de no haber existido dicha diferencia en el frenado de las ruedas del mismo eje, el evento lesivo muy probablemente se habría evitado. En este caso nos encontramos ante un defecto menor que, no obstante, tuvo incidencia en la afectación de la salud de un tercero. Pues bien, para establecer si de todos modos le es imputable objetivamente dicho resultado al conductor, debemos considerar el nivel de cuidado aplicable a tal caso. En este contexto, como plantea un sector de la doctrina ${ }^{43}$, el principio de insignificancia puede ser relacionado con una de las clasificaciones de la culpa, la que a su vez determina diversos ámbitos de responsabilidad del autor.

Como se sabe, en materia penal es posible distinguir entre culpa levísima, leve y grave $^{44}$. La culpa levísima, que es la que aquí interesa, es aquel descuido liviano, mínimo o ligerísimo, que se verifica en una situación peligrosa -pero no muy peligrosa-; o bien, aquel incumplimiento de un aspecto marginal del deber de cuidado; en ambos casos, con independencia de la magnitud del resultado ${ }^{45}$. A nuestro juicio, supuesto que la planta revisora advierta la existencia de un defecto menor, que no es reparado por el responsable del vehículo, y que este circule, en caso de generarse un resultado lesivo para terceros - producto del defecto menor-, este será atribuible a culpa levísima. En ese sentido, como nos hallaríamos ante un desperfecto que solo una persona extremadamente diligente repararía, salimos del ámbito de las medidas de cuidado que le son exigibles al hombre medio. A mayor abundamiento, en este supuesto se ha producido un incumplimiento marginal de las medidas de seguridad del vehículo. Tan marginal es el desperfecto, que el propio organismo encargado de controlar dichas medidas -la planta de revisión técnica- no lo considera para los efectos de conceder la certificación requerida, ni tampoco la normativa lo toma en cuenta para impedir la circulación del vehículo.

Justamente, los tipos penales culposos contra la vida y la salud, regulados en el Título X del Libro II del Código penal, y que pueden aplicarse al tráfico vial (artículos 490 y 492), no contemplan supuestos en los que se castigue lo que hemos denominado culpa levísima ${ }^{46}$. En efecto, mientras el artículo 490 demanda que el agente incurra en

${ }^{43}$ Véase Luzón Peña, D., Lecciones de Derecho Penal, Parte General, $2^{a}$ edición, Tirant lo Blanch, Valencia, 2012 , p. 311.

${ }^{44}$ Un análisis sobre la jurisprudencia chilena que recoge esta distinción en el ámbito médico puede verse en Martínez Lazcano, M., "La graduación del deber de cuidado en el delito culposo por Actos de mala praxis médica: un análisis dogmático, jurisprudencial y económico”, en Revista Política Criminal, vol. 6, núm. 12, diciembre 2011, pp. 245 y ss.

${ }^{45}$ Véase Luzón Peña, D., Lecciones de Derecho Penal, Parte General, $2^{\mathrm{a}}$ edición, Tirant lo Blanch, Valencia, 2012, p. 311.

${ }^{46}$ Con respecto al problema de la punibilidad de esta clase de culpa, véase, por todos Castronuovo, D., La colpa penale, Giuffrè, Milano, 2009, pp. 530 y ss. 
una "imprudencia temeraria", el artículo 492 exige infracción de reglamentos y "mera imprudencia o negligencia”. De esta forma, la verificación del tipo del artículo 490 supone que el agente actúe con culpa grave, o sea, aquella en que incurre una persona muy poco cuidadosa, que infringe considerablemente medidas elementales de cuidado ${ }^{47}$. En cambio, para que se aplique el tipo del artículo 492, el agente debe actuar con culpa leve, es decir, una forma de culpa que se sitúa a medio camino entre la levísima y la grave, y que, recurriendo al concepto de culpa del artículo 44 del Código civil, consiste en la falta de aquella diligencia o cuidado que los hombres emplean ordinariamente en sus negocios ${ }^{48}$.

Finalmente, con el criterio del fin de protección de la norma se busca excluir de la imputación objetiva la realización de todos aquellos peligros que no pretenden ser evitados por el precepto de cuidado infringido ${ }^{49}$. Al igual que los criterios de imputación objetiva que analizamos precedentemente, el del fin de protección de la norma encuentra en el tráfico vehicular un importante ámbito de aplicación ${ }^{50}$. En esa línea, se cita el ejemplo de quien, conduciendo a exceso de velocidad, atropella a un suicida que se lanza bajo sus ruedas, indicándose que la prohibición de velocidad excesiva no se dirige a evitar el atropello de un suicida ${ }^{51}$. El fin de protección de la norma constituye un principio que puede operar en distintos niveles, no obstante, se reconoce que su ámbito propio de aplicación es como criterio de imputación a propósito de la existencia o no de la relación de riesgo ${ }^{52}$. En otras palabras, se trata de un baremo que opera en la denominada imputación objetiva del resultado $\mathrm{o}^{53}$ o imputación objetiva en sentido estricto.

El control efectuado por las plantas de revisión técnica se dirige, específicamente, a supervisar el cumplimiento de determinadas condiciones de seguridad de los vehículos. Mediante el control de dichas condiciones se pretende precaver la verificación de ciertos eventos lesivos para la vida o la salud de terceros, que puedan ocurrir en el tráfico vehicular. Así, por ejemplo, la inspección que se realiza respecto del sistema de dirección del vehículo busca evitar que, producto de una falla en dicho dispositivo, el conductor pierda el control del automóvil y colisione con otro o atropelle a un peatón. Si una situación como la descrita se produce y nos hallamos ante un conductor que no

\footnotetext{
${ }^{47}$ Véase Luzón Peña, D., Lecciones de Derecho Penal, Parte General, $2^{\text {a }}$ edición, Tirant lo Blanch, Valencia, 2012, p. 309.

${ }^{48}$ Así Bustos, J., El delito culposo, Editorial Jurídica de Chile, Santiago, 1995, p. 51.

${ }^{49}$ En esa línea Roxin, C., Strafrecht Allgemeiner Teil, Tomo I, 4ª edición, Beck, München, 2006, pp. 390 y s.

${ }^{50}$ Véanse, entre otros, los ejemplos que plantea Roxin, C., "Sobre el fin de protección de la norma en los delitos imprudentes”, trad. de Diego-Manuel Luzón Peña, en Roxin, C., Problemas básicos del Derecho Penal, Editorial Reus, Madrid, 1976, p. 182.

51 Véase Mir, S., Derecho Penal, Parte General, 9a edición, Reppertor, Barcelona, 2011, p. 305.

52 Véase Corcoy, M., El delito imprudente. Criterios de imputación del resultado, $2^{\mathrm{a}}$ edición, B de f, Montevideo-Buenos Aires, 2005, pp. 574 y s.

53 Véase Gil Gil, A., "Reflexiones sobre la concepción de lo injusto, la determinación de la norma de cuidado y los criterios de imputación objetiva”, en Donna, E. A. (director), Delitos culposos-I, RubinzalCulzoni, Buenos Aires, 2002, p. 46.
} 
ha obtenido previamente la certificación requerida de la planta revisora, diríamos que el peligro que se ha intentado precaver por la norma, que impone el deber de inspeccionar el vehículo, se encuentra dentro del fin de protección de la misma. Contrariamente, por mucho que estemos imputando a un conductor que no ha obtenido la certificación de la planta revisora, si el evento lesivo se origina en una circunstancia diferente de aquellas que controla la planta de revisión técnica, tendríamos que concluir que dicho evento no le es imputable objetivamente, por encontrarnos fuera del fin protección de la norma en cuestión.

\section{BiBLIOGRAFÍA}

Abraldes, S., Delito imprudente y principio de confianza, Rubinzal-Culzoni, Buenos Aires, 2010. Anarte, E., Causalidad e imputación objetiva en derecho penal: estructura, relaciones y perspectivas, Universidad de Huelva, Huelva, 2002.

Bustos, J., El delito culposo, Editorial Jurídica de Chile, Santiago, 1995.

Cancio, M., "Aproximación a la teoría de la imputación objetiva”, en Bolaños, M. (compiladora), Imputación Objetiva y Dogmática Penal, Universidad de Los Andes, Mérida, 2005, pp. 87-122.

Castronuovo, D., La colpa penale, Giuffrè, Milano, 2009.

Corcoy, M., El delito imprudente. Criterios de imputación del resultado, $2^{\mathrm{a}}$ edición, B de f, MontevideoBuenos Aires, 2005.

Cury, E., Derecho penal, Parte general, $10^{a}$ edición, Ediciones Universidad Católica de Chile, Santiago, 2011.

Del Castillo, E., La imprudencia: autoría y participación, Dykinson, Madrid, 2007.

DutTge, G., Zur Bestimmtheit des Handlungsunwerts von Fabrlässigkeitsdelikten, Mohr Siebeck, Tübingen, 2001.

Etcheberry, A., Derecho Penal, Parte General, Tomo I, reimpresión de la $3^{a}$ edición, Editorial Jurídica de Chile, Santiago, 2010.

Feıjóo, B., "El principio de confianza como criterio normativo de imputación en el derecho penal: Fundamento y consecuencias dogmáticas”, en Derecho penal y criminología, vol. 21, núm. 69, 2000, pp. 37-76.

FERnÁndez, J. A., "El delito imprudente: la determinación de la diligencia debida en el seno de las organizaciones", en Revista de Derecho, Universidad Austral de Chile, vol. XIII, 2002, pp. 101-121.

Freund, G., "Fundamentos de la imprudencia punible. Una contribución desde la regulación alemana”, trad. de Jacobo Dopico Gómez-Aller y Laura Pozuelo Pérez, en Donna, E. A. (director), Delitos culposos-II, Rubinzal-Culzoni, Buenos Aires, 2002, pp. 79-117.

FrISCH, W., "Desarrollo, lineamientos y preguntas abiertas sobre la teoría de la imputación objetiva del resultado", trad. de Cecilia Hopp, en Frisch, W., Estudios sobre imputación objetiva, Legal Publishing, Santiago, 2012, pp. 9-35.

Garrido, M., Derecho Penal, Parte General, Tomo II, reimpresión de la $4^{a}$ edición, Editorial Jurídica de Chile, Santiago, 2007.

Gil Gil, A., "Reflexiones sobre la concepción de lo injusto, la determinación de la norma de cuidado y los criterios de imputación objetiva", en Donna, E. A. (director), Delitos culposos-I, Rubinzal-Culzoni, Buenos Aires, 2002, pp. 29-53.

Gössel, K. H., "Viejos y nuevos caminos de la teoría de la imprudencia (Fabrlässigkeitslehre)", en Donna, E. A. (director), Delitos culposos-I, Rubinzal-Culzoni, Buenos Aires, 2002, pp. 9-28. 
Hernández Basualto, H., “Art. 2o”, en Couso Salas, J. y Hernández Basualto, H. (directores), Código Penal Comentado, Parte General, Doctrina y Jurisprudencia, Legal Publishing, Santiago, 2011, pp. 105-123.

Hirsch, H. J., "Sobre lo injusto del delito imprudente", trad. de Eduardo Demetrio Crespo, en Revista de Derecho Penal y Criminología, 2a época, núm. 16, 2005, pp. 207-231.

Jaковs, G., "La imputación objetiva, especialmente en el ámbito de las instituciones jurídicopenales del 'riesgo permitido', la 'prohibición de regreso' y el 'principio de confianza'”, trad. de Enrique Peñaranda, en Jakobs, G., Estudios de Derecho Penal, Civitas, Madrid, 1997, pp. 209-222.

KINDHÄUSER, U., "Acerca de la delimitación entre dolo e imprudencia”, trad. de Orlando Humberto De La Vega, en Revista Jurídica - Mario Alario D’Filippo, vol. 4, núm. 1, 2012, pp. 8-18.

KIndhäuser, U., “¿Qué es la imprudencia?”, trad. de Juan Pablo Mañalich, en La Ciencia Penal en la Universidad de Chile, Libro Homenaje a los Profesores del Departamento de Ciencias Penales de la Facultad de Derecho de la Universidad de Chile, LOM, Santiago, 2013, pp. 217-228.

Luzón Peña, D., Lecciones de Derecho Penal, Parte General, $2^{a}$ edición, Tirant lo Blanch, Valencia, 2012

Mañalich, J. P., "La imprudencia como estructura de imputación”, en Revista de Ciencias Penales, 6a época, vol. XLII, núm. 3, 2015, pp. 13-36.

Martínez Lazcano, M., "La graduación del deber de cuidado en el delito culposo por Actos de mala praxis médica: un análisis dogmático, jurisprudencial y económico”, en Revista Política Criminal, vol. 6, núm. 12, diciembre 2011, pp. 214-251. Disponible en: http://www.scielo. cl/pdf/politcrim/v6n12/art01.pdf [visitado el 7/10/2016].

Mayer Lux, L. y Vera Vega, J., "Relevancia jurídico-penal de la conducción vehicular sin la correspondiente licencia”, en Doctrina y Jurisprudencia Penal, Edición Especial, 2014, pp. 115-132.

Mir, S., Derecho Penal, Parte General, 9a edición, Reppertor, Barcelona, 2011.

Ovalle, G., "Imprudencia y cognición", en Doctrina y jurisprudencia penal, $n^{\circ} 4$. Imprudencia penal. Cuestiones generales, 2011, pp. 31-43.

Reyes, I., "Una aproximación a la imputación a título de imprudencia en el Código penal chileno", en Revista de Derecho de la Pontificia Universidad Católica de Valparaíso, vol. XLVII, 2016, pp. 245-278.

Reyes, I., "Un concepto de riesgo permitido alejado de la imputación objetiva", en Revista Ius et Praxis, núm. 1, 2015, pp. 137-170.

Rojas, Ch., "Alcance y aplicabilidad de la nulidad administrativa a los actos emanados de particulares en el ejercicio de funciones públicas”, en Ferrada, J. C. (coordinador), La nulidad de los actos administrativos en el derecho chileno, Legal Publishing, Santiago, 2013, pp. 77-155.

Rosas, J. I., "La delimitación del deber de cuidado en la imputación de responsabilidad penal por imprudencia médica", en Doctrina y jurisprudencia penal, $n^{\circ} 5$. Imprudencia penal médica, 2011, pp. 3-33.

Roxin, C., "Sobre el fin de protección de la norma en los delitos imprudentes", trad. de DiegoManuel Luzón Peña, en Roxin, C., Problemas básicos del Derecho Penal, Editorial Reus, Madrid, 1976, pp. 181-199.

Roxin, C., Strafrecht Allgemeiner Teil, Tomo I, 4a edición, Beck, München, 2006.

Schünemann, B., "Las reglas de la técnica en Derecho penal", trad. de Manuel Cancio y Mercedes Pérez, en Schünemann, B., Obras, Tomo II, Rubinzal-Culzoni, Buenos Aires, 2009, pp. 243-283.

Silva Sánchez, J., "Deberes de los miembros de un Consejo de Administración [a propósito de la STS núm. 234/2010 (Sala de lo Penal), de 11 de marzo]”, en InDret, 2011, pp. 1-5. Disponible en: http://www.indret.com/pdf/editorial_2.11cast.pdf [visitado el 07/10/2016]. 
VAN Weezel, A., "Parámetros para el enjuiciamiento de la infracción al deber de cuidado en los delitos imprudentes", en Revista Chilena de Derecho, vol. 26, núm. 2, 1999, pp. 323-336.

Welzel, H., Derecho penal alemán, trad. de Juan Bustos y Sergio Yáñez, $4^{a}$ edición, Editorial Jurídica de Chile, Santiago, 1997.

Zugaldía Espinar, J. M., "La infracción del deber individual de cuidado en el sistema del delito culposo", en Anuario de Derecho Penal y Ciencias Penales, 1984, pp. 321-332. 
